\title{
Barotrauma and Successful Release of Fish Caught in Deep Water ${ }^{1}$
}

\author{
Betty Staugler, Holly Abeels, Angela Collins, Shelly Krueger, and Kai Lorenzen²
}

Experienced offshore anglers are all too familiar with having to release fish that are too small, out of season, or just bycatch. If you catch a fish you are not going to keep, help it survive and get back to the deep! Healthy released fish will have a greater chance to grow and reproduce, which benefits fish populations and the future of fisheries. For fish caught in deeper water, part of successful release involves relieving barotrauma in fish whose swim bladders have expanded during their ascent to the surface, leaving them too buoyant to descend on their own. This publication provides an overview of barotrauma and barotrauma mitigation methods.

\section{What is barotrauma?}

Barotrauma is an injury caused by a change in pressure. A reef fish caught from deep water often will experience an expansion of gases in its swim bladder as it is brought to the surface. This may result in an overinflated or ruptured swim bladder as well as other pressure-related injuries, creating a condition called barotrauma. When this occurs, fish may be unable to return to depth after you release it.

Physical signs of barotrauma include protrusion of the stomach from the fish's mouth, bulging eyes, bloated belly, bubbling scales, and distended intestines.
Barotrauma severity and likelihood increases with depth; most cases occur deeper than 30 feet. Certain species are more susceptible than others, and high temperatures may increase the severity of barotrauma.
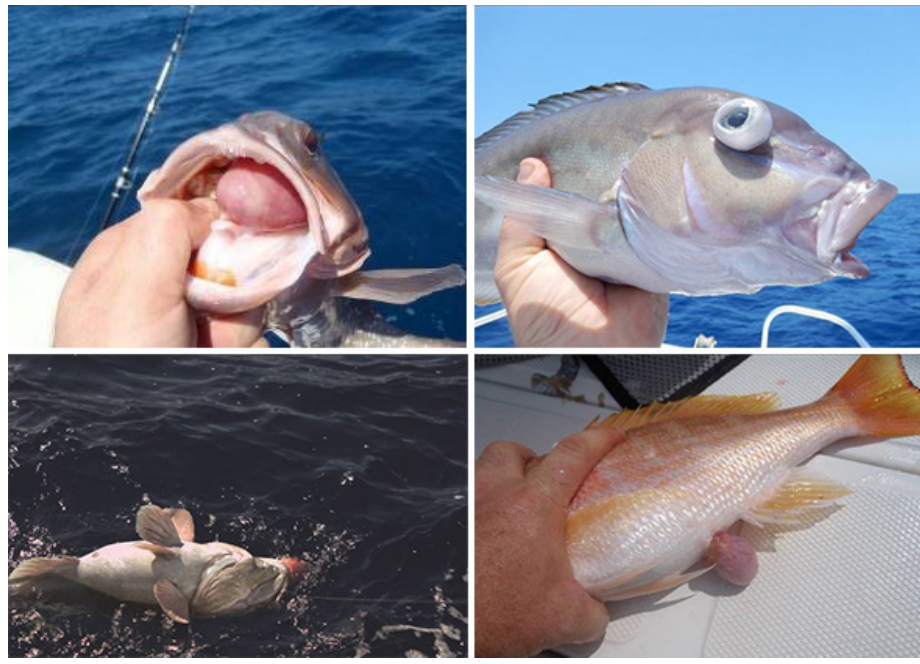

Figure 1. Signs of barotrauma include: everted or protruding stomach coming out of the mouth (top left); bulging eyes (top right); bloated belly (bottom left); distended intestines (bottom right).

Credits: Florida Sea Grant

1. This document is ED-1, one of a series of the Florida Sea Grant College Program, UF/IFAS Extension. Original publication date August 2018. Visit the EDIS website at http://edis.ifas.ufl.edu.

2. Betty Staugler, UF/IFAS Extension Florida Sea Grant agent, Charlotte County; Holly Abeels, UF/IFAS Extension Florida Sea Grant agent, Brevard County; Angela Collins, UF/IFAS Extension Florida Sea Grant agent, Manatee County; Shelly Krueger, UF/IFAS Extension Florida Sea Grant agent, Monroe County; and Kai Lorenzen, professor, School of Forest Resources and Conservation, Program in Fisheries and Aquatic Sciences; UF/IFAS Extension, Gainesville, FL 32611.

The use of trade names in this publication is solely for the purpose of providing specific information. UF/IFAS does not guarantee or warranty the products named, and references to them in this publication do not signify our approval to the exclusion of other products of suitable composition.

The Institute of Food and Agricultural Sciences (IFAS) is an Equal Opportunity Institution authorized to provide research, educational information and other services

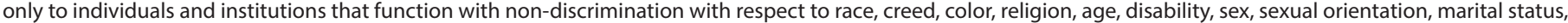
national origin, political opinions or affiliations. For more information on obtaining other UF/IFAS Extension publications, contact your county's UF/IFAS Extension office. U.S. Department of Agriculture, UF/IFAS Extension Service, University of Florida, IFAS, Florida A \& M University Cooperative Extension Program, and Boards of County Commissioners Cooperating. Nick T. Place, dean for UF/IFAS Extension. 
No one likes the sight of floaters. Fishery regulations that require fish to be released will only be effective if fish survive. Reducing discard mortality could lead to more fishing opportunities in the future.

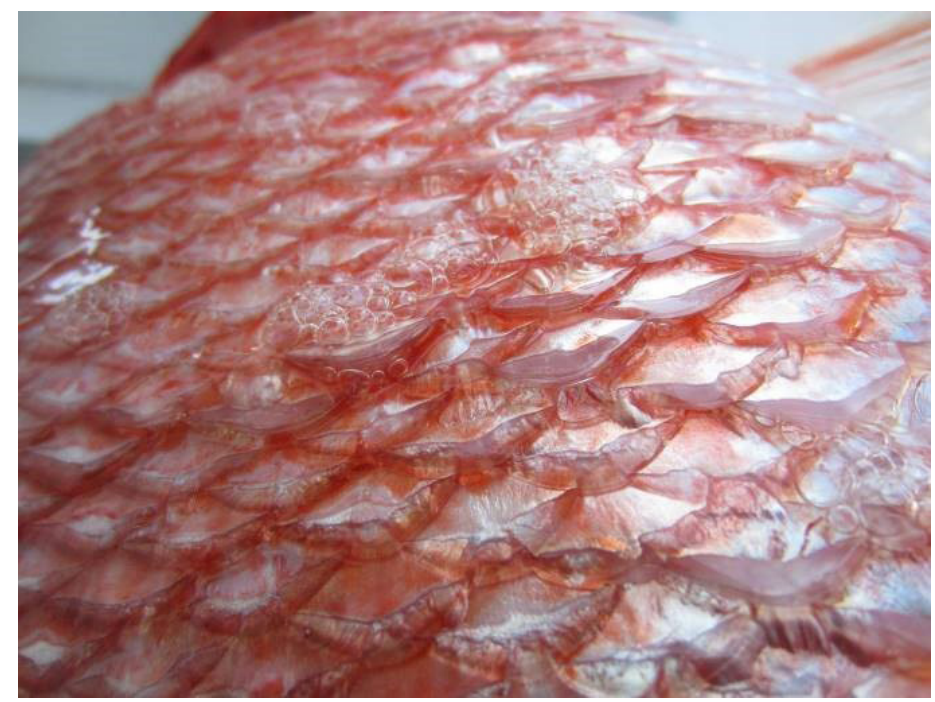

Figure 2. Signs of barotrauma also include bubbling scales, and inability to return to depth.

Credits: Hayden Staley, Florida Fish and Wildlife Conservation Commission

\section{What can you do? Use Venting or Weighted Descent to Help a Fish with Barotrauma}

There are two ways you can help fish suffering from barotrauma.

1. Venting releases gas that has expanded within the swim bladder so that the fish can return to depth on its own.

2. Weighted descent returns fish to capture depth quickly.

Studies show that both approaches are effective when applied correctly. The approaches have different advantages and disadvantages - choose the one that is best for you, and make sure you know how to do it correctly.

It is always important to work quickly when releasing fish. The faster a fish gets back in the water, the greater its chances of survival. Use gear that minimizes fight time to reduce lactic acid build up and stress, and be as efficient as possible on deck to ensure quick release to the water. Gas expansion continues and barotrauma severity increases the longer the fish is at the surface.

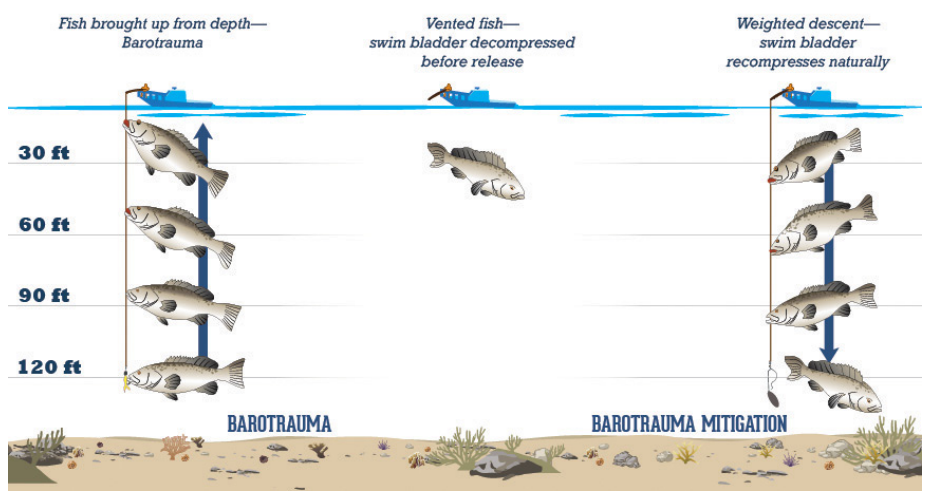

Figure 3. The quicker the fish gets back in the water, the better it will do. Use gear that minimizes fight time to reduce lactic acid build up and stress. On deck, handle the fish as quickly as possible for rapid release.

Credits: Florida Sea Grant

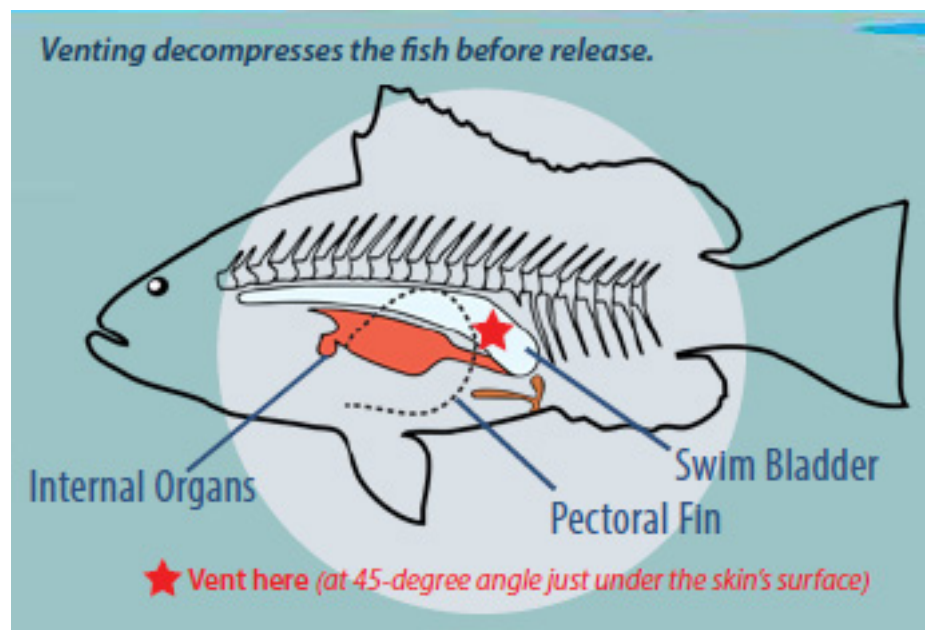

Figure 4. Research has shown that venting works when performed properly.

Credits: Florida Sea Grant

\section{Venting}

Venting is a traditional barotrauma mitigation method that is particularly suited for situations where you must handle many fish quickly. Data shows that most fish caught at depths shallower than 125 feet generally heal quickly and resume normal activities within 24-48 hours if they are vented appropriately.

Venting is quick, and the tools are cheap, but there is a risk of injuring or killing the fish if you don't do it properly.

Venting involves the use of a sharp, hollow instrument that is inserted through the muscle to puncture the swim bladder wall and release the gas that expanded within the swim bladder upon ascent. Many varieties of venting 
tools are available. You can also make your own from any sharp and hollow instrument. Knives and ice picks are not suitable, because they do not provide an adequate escape route for the gas.

To properly vent, lay the fish on its side (on a cool, wet surface). Venting tools should be inserted at a 45 -degree angle, under a scale at the trailing edge of the pectoral fin, just deep enough to release trapped gas from the swim bladder. Never insert venting tools into a fish's belly or back or into its stomach if it is protruding from its mouth.
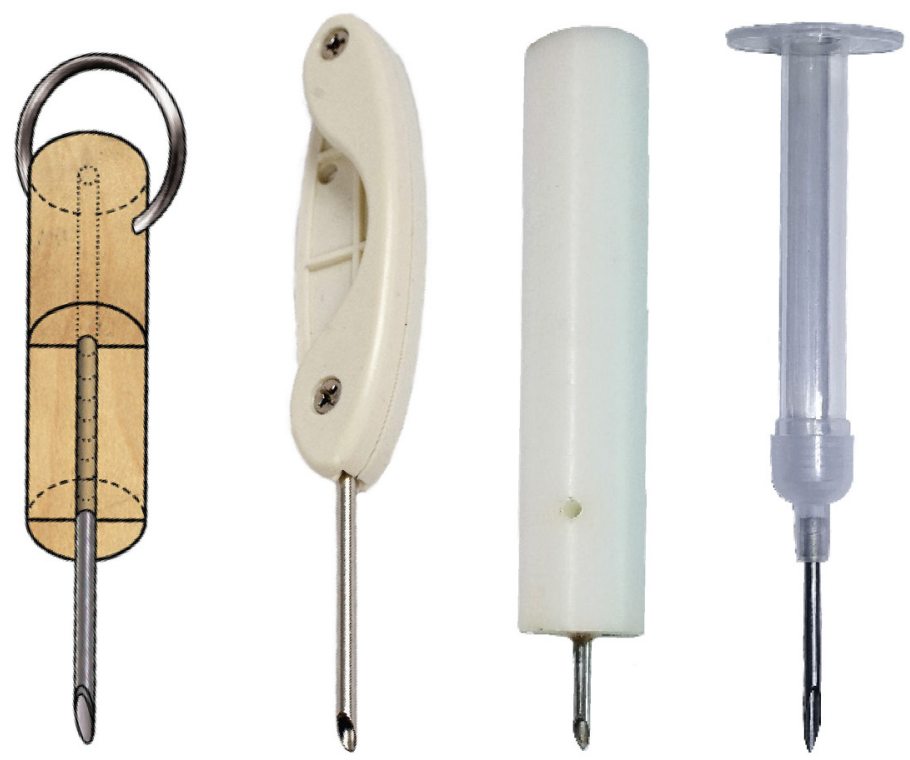

Figure 5. Common venting tools. (Pictured images do not imply commercial endorsement.)

Credits: Florida Sea Grant

\section{PROS}

- Fast and particularly suited for situations where you must handle many fish quickly.

- Increases fish survival rates when performed correctly.

- Tools are small, inexpensive, and convenient.

\section{CONS}

- All sharp tools involve puncture risk-to you as well as to the fish.

- Research indicates that about 50 percent of anglers vent incorrectly resulting in injury or death to the fish.

- Vented fish may be more susceptible to predators like dolphins and sharks because they are released at the surface and must swim down on their own.

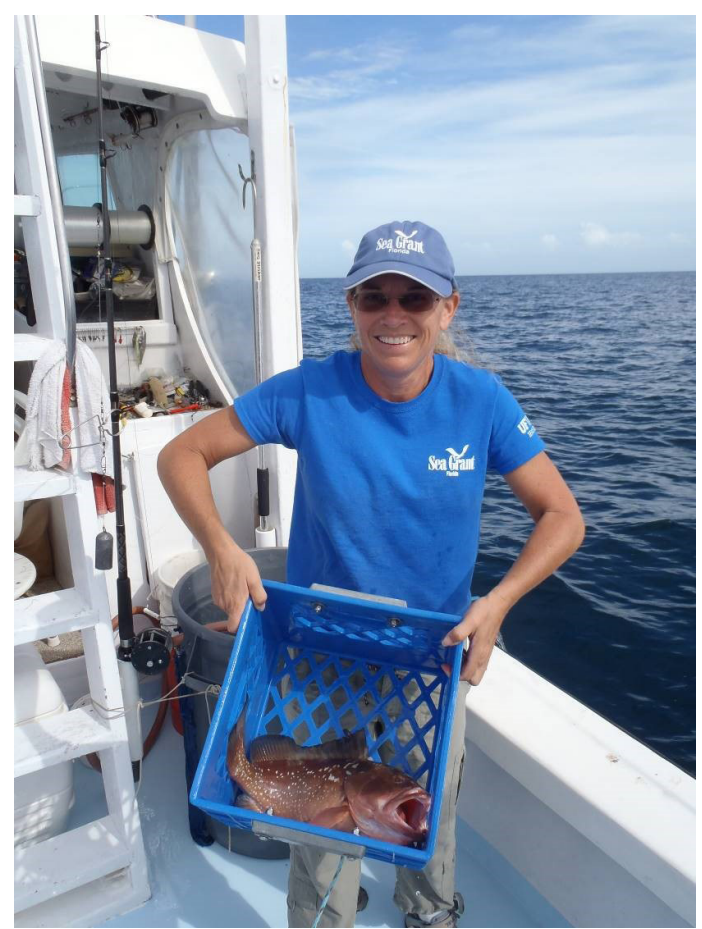

Figure 6. A weighted milk crate placed upside down in the water is one tool used for weighted descent.

Credits: Florida Sea Grant

\section{Weighted Descent}

Descending is another addition to the barotrauma mitigation toolbox and is a method particularly suited for situations when you are not sure how to vent, or when you are worried about potential predation on released fish.

Descending involves using a weighted device that attaches to or encloses the fish and forcibly sinks the fish. Returning it to depth on a weight will recompress expanded gas within the fish's body, allowing it to regain its natural buoyancy and swim away.

Devices may fall into one of three general categories: mouth grips, inverted hooks, and fish elevators.

Mouth grips are attached to a rod and reel or hand line, clamp to the mouth of the fish, and use a pressure-sensor release mechanism (releases fish automatically at a predetermined depth selected by the angler) or a weighted spring-release mechanism (lets go of fish when the angler gives a sharp tug on the line or when the weight hits the bottom).

Inverted hooks work like mouth grip devices but are inserted through the hole made by the hook. Once the fish descends deeply enough to reverse the effects of barotrauma, the angler gives a few short jerks on the line, allowing the fish to get off the inverted hook. 


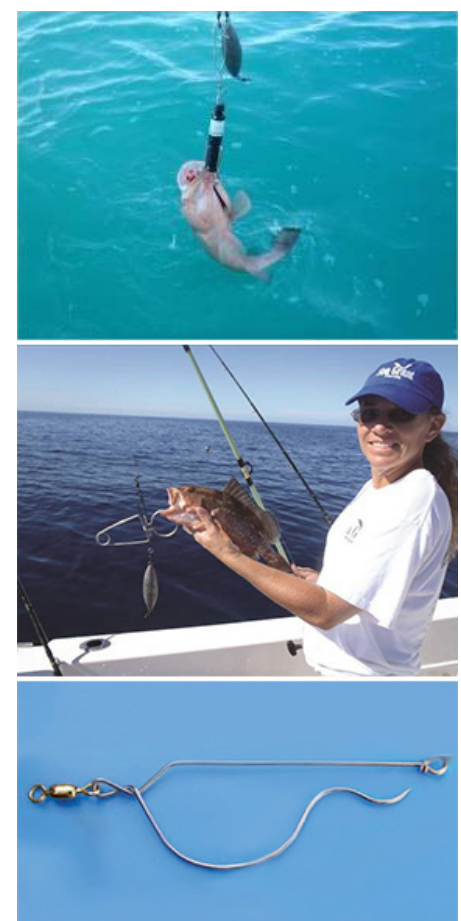

Figure 7. Common weighted descent tools include: pressurizedrelease tools (top); weighted spring-release tools (middle); and S-shaped wire hook clips (bottom).

A third option is the fish "elevator," which involves an inverted container such as a milk crate with a rope attached to the top and weights on the bottom. This creates a bottomless cage that brings fish back down to depth. When the fish recompresses, it is able to swim out of the bottom of the container on its own.

Common weighted descent concerns among anglers include:

- Descending gear will scare away fish

- Predators are attracted to the fish and the tool

- Descending gear is complicated and time-consuming to use

However, most descending gear is relatively simple, and there is minimal evidence of decreased catchability or increased predation. Every situation is different though, and some anglers may encounter different obstacles depending on their location and situation.

\section{PROS}

- Non-invasive technique minimizes injury

- No sharp objects required

- Easy to learn

- Minimize predation risk by returning fish to the bottom as quickly as possible

\section{CONS}

- More gear taking up space on boat

- May cost more than venting tools

- Added time involved in pulling the weighted gear up to the surface

- Not every tool works for every fishing situation

\section{Why help fish with barotrauma?}

Recreational anglers, commercial fishing operations, and fisheries managers support the use of barotrauma mitigation strategies to increase survival rates of released fishes. Fishery regulations that require fish to be released will only be effective if fish survive. Reducing discard mortality could lead to more fishing opportunities in the future.

\section{Careful Handling Points}

- The quicker the fish gets back in the water, the greater its chance of survival.

- Use gear that minimizes fight time to reduce stress on the fish.

- Handle fish quickly on deck by having dehooking and barotrauma tools ready for use.

- Use barotrauma tools properly to give the fish the best chance of survival.

- Reduce the amount of time fish are at the surface or in open water and vulnerable to predators.

This information represents the best available science as interpreted by the Florida Sea Grant Fisheries Work Action Group. For more information, visit www.catchandrelease. org or contact Betty Staugler, UF/IFAS Extension Florida Sea Grant Agent at staugler@ufl.edu or 941-764-4346. 